\title{
Sarkoidose
}

\section{Mykobakterien als Auslöser?}

\author{
Die Sarkoidose ist eine interstitielle Lungenerkrankung mit noch \\ weitgehend unbekannter Ätiologie. Allerdings verdichten sich \\ Hinweise auf eine ätiologische Rolle von Mykobakterien. \\ Im Hinblick auf die Therapie der chronischen Verlaufsformen \\ zeichnen sich neue Behandlungsansätze ab.
}

— Die Sarkoidose ist eine hoch komplexe Erkrankung mit einer hohen Variabilität klinischer Phänotypen. Sowohl die Organmanifestationen als auch die klinischen Verläufe weisen eine beachtliche Heterogenität auf. Charakteristisch ist die Bildung epitheloidzelliger Granulome und eine verstärkte Immunantwort. Auch wenn prinzipiell jedes Organ betroffen sein kann, weisen etwa 90\% der Patienten eine Lungenbeteiligung auf.

In Europa liegt die Prävalenz bei etwa 40-50 pro 100000 Einwohner. Eine überdurchschnittliche Häufung findet man bei Nordeuropäern und der afroamerikanischen Bevölkerung in den USA, berichtete Prof. Dr. David R. Moller, Baltimore/ USA.

\section{Indizien für mykobakterielle Ätiologie}

Als Auslöser werden zum einen eine genetische Disposition und zum anderen eine Exposition gegen noch unbekannte Antigene angenommen. Die Ähnlichkeit der Granulome mit den entsprechenden Veränderungen bei der Tuberkulose führte zu der Vermutung, dass Mykobakterien auch bei der Entstehung der Sarkoidose beteiligt sein könnten. Mittels PCR ist es in zahlreichen Studien gelungen, mykobakterielle DNA nachzuweisen - allerdings mit erheblichen Schwankungen zwischen den einzelnen Studien.

Moller und Mitarbeiter fanden in Sarkoidosegewebe ein pathogenes Antigen, dass sie als mykobakterielles KatalasePeroxidase-Protein (mKatG) identifizieren konnten. Bei 85\% der Sarkoidosepatienten in den USA und in Schweden haben die Forscher mKatG-reaktive CD4-
positive-Zellen in der Lunge nachgewiesen (Chen ES et al. J Immunol 2008). Zirkulierende mKatG-reaktive T-Zellen fanden sich bei Patienten mit chronisch aktiver, nicht aber bei Patienten mit inaktiver Sarkoidose. Diese Befunde unterstreichen die bisherigen Vermutungen, dass Mykobakterien tatsächlich eine relevante Rolle in der Ätiologie der Sarkoidose spielen und dass mKATG ein spezifisches pathogenes Antigen ist.

\section{Neue Therapien auf dem Prüfstand}

Die Sarkoidose heilt bei mehr als der Hälfte der Patienten folgenlos aus. Bei chronischem Verlauf mit Organbeteiligung ist sie aber schwierig zu behandeln. Die akuten Symptome sprechen zwar gut auf Kortikosteroide an. Aber nach der Therapie kann die Rezidivrate sogar steigen. Als Alternativen und bei Rezidiven während des Ausschleichens der Kortikosteroide werden Methotrexat, Cyclophosphamid, Azathioprin und Leflunomid eingesetzt, so Dr. Antje Prasse, Freiburg. Langfristig können die konventionellen immunsuppressiven Therapien zu erheblichen Nebenwirkungen führen, sodass Bedarf an neuen Therapeutika besteht, die selektiver und besser verträglich sind.

Zwei placebokontrollierte Studien haben gezeigt, dass der TNF- $\alpha$-Blocker Infliximab die pulmonale Funktion von Sarkoidosepatienten verbessern kann (Baughman RP et al. Am J Respir Crit Care Med 2006; Rossman MD et al. Sarc Vasc Diff Lung Dis 2006). Auch bei Patienten mit Neurosarkoidose und Hautläsionen, die mit konventionellen Immunsuppressiva schwierig therapierbar sind, führte die Anti-TNF-Therapie zu einer Verbesserung.

Eine weitere viel versprechende Therapieoption sei die Verabreichung von VIP (Vasoaktive Intestinale Peptide), berichtete Prasse. VIP habe zwei Effekte, die Modulation von regulatorischen T-Zellen (Tregs) sowie eine Reduktion der TNF-aProduktion. Erste Studiendaten zeigen, dass inhalativ zugeführtes VIP (Aviptadil) die Anzahl von Tregs in der bronchoalveolären Lavage (BAL) erhöht und ihre Funktion verbessert (Prasse A et al. Am J Respir Crit Care Med. 2010). Zusätzlich führt die VIP-Inhalation zu einer Reduktion der TNF- $\alpha$-Produktion.

\section{Abdol A. Ameri}

Quelle: Hot Topic ${ }_{\text {} F}$ Frontiers in Sarcoidosis research", ERS-Kongress 2010 in Barcelona

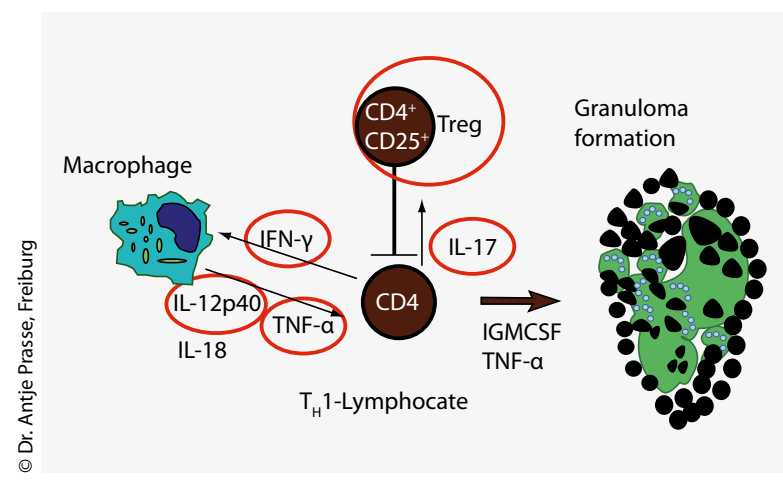

Die Immunpathogenese der Sakoidose basiert auf einer starken Interaktion von Makrophagen und T-Zellen, die letztlich über TNF-a und GMCSF zur Granulombildung führt. Regulatorische TZellen (Treg) modulieren diese Interaktion. Die potenziellen therapeutischen Ansatzpunkte sind eingekreist. 